\title{
Emigrar para vivir, servir para inmigrar \\ Legislaciones para las inmigraciones de judíos a América y Colombia entre 1880 y $1930^{*}$
}

Recibido: 27 de agosto de 2014 | Aprobado: 23 de octubre de 2014

\section{Mateo Navia Hoyos** \\ ultimaletra@gmail.com}

\begin{abstract}
Resumen
En este artículo se presenta una aproximación al tratamiento otorgado a los judíos migrantes de Asia a América y Colombia entre 1880 y 1930 , principalmente desde las legislaciones que se produjeron. Dicho contexto legal, acompañado de la mención a la discusión sobre la cuestión de la raza que se realizó en 1920, permiten plantear que en el contexto de la modernización que se estaba produciendo en el continente americano, los judíos que ingresaran a los países correspondientes debían comprometerse con los programas de desarrollo y progreso de las naciones.
\end{abstract}

\section{Palabras clave}

Judíos, inmigración, América, Colombia, legislaciones.

\section{Emigrate to live, Serve to Immigrate. American and Colombian Immigration Legislation for Jews between 1880 and 1930}

\begin{abstract}
This article takes a look at the treatment given to migrant Jews from Asia to America and Colombia between 1880 and 1930, mainly based on the laws that were created. This legal context, accompanied by a reference to the discussion on the issue of race that was held in 1920, allows us to think that in the context of the modernization that was taking place on the American continent, Jews who entered the relevant countries had to engage in the nations' development and progress programs.
\end{abstract}

\section{Key words}

Jews, inmigration, America, Colombia, legislation.
* Este artículo presenta resultados de mi tesis de maestría en historia presentada en la Universidad Nacional de Colombia, sede Medellín, en 2012, intitulada Judios en Colombia durante la segunda guerra mundial (1939-1945). Director: Luis Javier Ortíz Mesa.

** Magíster en Historia por la Universidad Nacional de Colombia, sede Medellín, y candidato a Doctor en Historia por la misma Institución. Integrante del Grupo de Investigación "Prácticas, saberes y representaciones en Iberoamérica" de la Universidad Nacional de Colombia, sede Medellín. 


\section{Introducción}

Cuando se emprende una investigación histórica sobre una población específica, es necesario informarse sobre el contexto en el cual esta se encontraba, pues permite establecer las condiciones o no, que la determinaban. En esta perspectiva, y atendiendo a lo planteado por Ruggiero Romano, a saber, que "la investigación histórica enseña que no [... existe] solamente el texto, sino sobre todo el contexto" (Florescano, 2012: 109), en este artículo se presentan algunas de las legislaciones que se produjeron para la inmigración judía a América y Colombia entre finales del siglo XIX y las primeras décadas del siglo XX.

Antes de iniciar la mencionada presentación, es importante anotar, como lo realiza Haim Avni, el aumento demográfico impactante del pueblo judío en Asia, incluida Europa, durante el siglo XIX, y el motivo de su persecución.

En primera instancia debe consignarse que la población judía migrante de Asia a América, pasó de 2.500.000 personas en 1800, a 10.620.000 en 1900 (Cfr. Avni, 1992: 119). ${ }^{1}$ En segunda instancia, debe recordarse que el 13 de marzo de 1881, el zar Alejandro II de Rusia fue asesinado por un grupo de revolucionarios, entre los cuales se reportó la participación de una joven judía. A partir de ello, la Casa Real impulsó que fuesen culpados los judíos del crimen cometido, logrando utilizar en adelante, incluso hasta la revolución de febrero de 1917, "a las masas judías como pararrayos de la rebeldía popular" (Avni, 1992: 120). De ese modo, durante más de treinta años, desde 1881, las matanzas de judíos en Rusia estuvieron acompañadas con algunas leyes mediante las cuales se les prohibió residir en el campo, se les restringió el acceso a las escuelas y universidades, y se les redujeron las posibilidades para obtener empleo.

La emigración se convirtió entonces en la única solución a la situación en la que se encontraban los judíos que habitaban en Rusia, faltándoles aún por reconocer las condiciones particulares de los países donde pudiesen ingresar. Al respecto, mientras en Estados Unidos los inmigrantes judíos fueron partícipes de la modernización

\footnotetext{
Para referir las migraciones sefardíes a Estados Unidos, Avni destaca el deterioro económico del imperio turco y las guerras balcánicas, entre la década del 80 del siglo XIX y la primera década del siglo XX (Cfr. Avni, 1992: 148-149).
} 
industrial, en América Latina y Canadá su injerencia se concentró en las actividades agrícolas y comerciales.

\section{Emigrar para vivir}

Avni consigna que 2.433.000 inmigrantes judíos se radicaron en Estados Unidos durante las dos últimas décadas del siglo XIX, cuando el despliegue industrial se manifestó de manera fundamental en la expansión de los ferrocarriles, pues de un total de 128.800 kilómetros en 1880, se pasó a 305.900 veinte años más tarde (Cfr. Avni, 1992: 121). Más aún, como lo consignó el caldense Joaquín Ospina Vallejo, las corrientes migratorias judías contribuyeron al adelanto de los Estados Unidos, de un modo tal que

"[n]o hay campo de actividad en el que no hubiesen participado. En las letras, en las ciencias y en las artes han producido hombres que le hacen honor a los Estados Unidos. Han tomado parte activa en la política interior y exterior del país y hay gobernadores de estado, senadores, representantes, diplomáticos y altos empleados administrativos judíos. Muchas industrias y la potencia económica y bancaria de los Estados Unidos, le deben incontables servicios a su población hebrea" (Ospina, 1939: 105).

En Canadá, en cambio, el proceso de inmigración tuvo como prioridad la colonización de la pampa hacia el océano Pacífico, fundamentalmente para el trabajo agrícola. Sobre dicho proceso apunta Avni: "La población judía de Canadá aumentó rápidamente después de 1881, año en el cual se censaron sólo 2.456 judíos. Al final de la novena década del siglo, llegaba a 6.586 personas, y en los censos de 1901 y 1911 a 16.717 y 75.838, respectivamente" (Avni, 1992: 207).

En América Latina, por su parte, los inmigrantes judíos encontraron un entorno diferente al de Estados Unidos pero semejante al de Canadá, a saber, administraciones estatales volcadas hacia el mejoramiento de la producción agrícola, vía mediante la cual podría lograrse el progreso del país. Tales intenciones se reflejaron de manera clara en las políticas inmigratorias de países como Argentina, Paraguay, Bolivia, Perú, Honduras, México y Brasil, desde los cuales se realizaron ofertas de tierra a habitantes de Asia que tuviesen interés en inmigrar. No puede omitirse de lo anterior, sin embargo, que 
la injerencia de las ideas positivistas, claramente presentes en México con Porfirio Díaz, o en la recientemente proclamada República de Brasil, incidió en las decisiones políticas sobre la inmigración, preferentemente europea, que redundaría en el fortalecimiento de la nación, tanto porque podría mejorar "la raza", como porque podría reemplazar la esclavitud (Cfr. Avni, 1992: 158-163).

En el contexto de lo que venimos tratando, al lograr los inmigrantes su inclusión en los procesos de modernización industrial y agrícola, los sentimientos nacionales comenzaron a mezclarse. De un lado, hubo aceptación porque los inmigrantes ayudaban en el despliegue de las actividades económicas, y su introducción en las actividades sociales e incluso culturales, eran positivas, más aún si contribuían, al parecer, genéticamente, en el mejoramiento de "la raza". De otro lado, fueron contemplados con sospecha, provocando reacciones de rechazo, porque, llegó a decirse, su participación podría incidir de manera negativa en la identidad nacional, ya fuera porque constituían "una raza inferior" o porque llegaran a alcanzar un paulatino poder en varias esferas sociales. Por tanto, las políticas de inmigración comenzaron a tener regulaciones en las primeras décadas del siglo XX, mediante estipulaciones y restricciones de diversa índole que protegieran los procesos modernizadores, clave fundamental de las emergentes naciones latinoamericanas, canadiense y estadounidense.

En esta perspectiva es relevante mencionar las dos leyes que restringieron la inmigración a los Estados Unidos en 1917 y 1924, e incluso en 1929. En primer lugar, el Acto conocido como Ley Burnett de 1917, con el cual se estipuló como condición de ingreso la alfabetización de los inmigrantes que fuesen mayores de 16 años, se incrementó la tarifa al momento del ingreso, se prohibió la admisión de alcohólicos, vagos y personas de constitución inaceptable, y a quienes hubiesen nacido en un entorno geográfico definido como "Asiatic Barred Zone" que exceptuó a los japoneses y filipinos. En segundo lugar, la llamada Ley de cuotas, o el Acto de inmigración de 1924 (Johnson-Reed Act), que limitó la admisión para los inmigrantes. En dicho texto, queda manifiesto que el presidente de los Estados Unidos -John Calvin Coolidge Jr., elegido para el periodo 1923-1929-, considera que "[1] a cuota anual de cualquier nacionalidad será de dos por ciento del número de personas de origen extranjero residente de esa nacionalidad en el territorio continental 
de Estados Unidos según lo determine el censo de los Estados Unidos de $1890 " .{ }^{2}$ Con ello lograron reducirse de manera drástica las inmigraciones del sur y del este europeo, hasta conseguir en 1929, una ley que "fijó un tope de 150.000 inmigrantes por año"; y, con ello, continúa Avni, "[e]l número anual de los principales países de emigración de los judíos -Rusia, Polonia, Rumanía, Hungría y Turquía-, que se había fijado en la ley de 1921 en 71.202 personas, se redujo en la de 1929 a 10.698" (Avni, 1992: 125).

En Canadá, por el contrario, la discusión entre los partidarios o adversarios de la drástica ley de cuotas que se había aplicado en los Estados Unidos, no puso "en entredicho la legitimidad de la acción de los políticos judíos a favor de su colectividad, y este es uno de los síntomas del arraigo de los judíos, como individuos y como comunidad, en el panorama político y social de Canadá" (Avni, 1992: 216), que pudo verse reflejado en los datos del censo de 1931, en el cual muchos judíos aparecieron con ocupaciones como abogados, médicos, profesores y periodistas.

En países como México, Jamaica, Brasil, Uruguay, Cuba, Haití, República Dominicana, Surinam y Costa Rica, fueron acogidos los judíos gracias a las disposiciones tolerantes y abiertas de sus administraciones, pero en países como Chile, Argentina y Venezuela, la atmósfera se tornó hostil e incluso peligrosa. Por su parte, en países como Colombia, Ecuador, Perú, Bolivia y Paraguay, la situación fue menos agobiante debido a las escasas demandas de inmigrantes judíos (Cfr. De Lange, 1992: 160-164). Países como Honduras, Nicaragua, El Salvador y las Guayanas atrajeron poco la atención de los judíos, pues se trataba de lugares desconocidos para muchos de ellos.

\section{Inmigrar para servir}

Como se prometió al inicio de este artículo, a continuación serán presentados los virajes de aceptación y rechazo que se produ-

\footnotetext{
"EE. UU. Oficina de Inmigración, Informe Anual del Alto Comisionado General de Inmigración”, 1924 , p. 24 y ss., "Ley de inmigración de 1924. 26 de mayo de 1924".

En: http://translate.google.com.co/translate?hl=es\&sl=en\&u=http://staff.imsa.edu/socsci/jvictory/immigration_progressive/anti_immigration1926.htm\&ei=X2B_T8_bIoKY8gT-sIiyBw\&sa=X\&oi=trans late\&ct $=$ result $\&$ resnum $=10 \&$ ved $=0 \mathrm{CG} 4 \mathrm{Q} 7 \mathrm{gEwCTgK} \& \mathrm{prev}=/$ search $\% 3 \mathrm{Fq} \% 3 \mathrm{DThe} \% 2 \mathrm{BImmigratio}$ n\%2BAct\%2Bof\%2B1924\%2B\%252B\%2Bespa\%25C3\%25B1ol\%26start\%3D10\%26hl\%3Des\%26s a\%3DN\%26biw\%3D1366\%26bih\%3D667\%26prmd\%3Dimvns. (Visitado el 5 de abril de 2012). Al respecto, Cfr. "U.S. Department of State. Office of the Historian", "The inmigration Act of 1924 (The Johnson-Reed Act). En: http://history.state.gov/milestones/1921-1936/ImmigrationAct. Visitado el 5 de abril de 2012.
} 
jeron hacia los extranjeros de un modo más general desde algunas legislaciones aplicadas a finales del siglo XIX y durante las primeras dos décadas del XX en Colombia, y posteriormente se encadenarán dos aspectos importantes que permiten traslucir la situación de los judíos durante aquellas décadas: la discusión sobre "la raza" que se dio en 1920, y las consideraciones sobre la religión estipuladas en la Constitución de la República de Colombia de 1886, que condicionaron la posibilidad de inmigración de algunos judíos al territorio nacional.

Rodrigo de J. García Estrada, quien ha estudiado la influencia extranjera en el desarrollo de las regiones que forman la nación colombiana, mediante sus aportes al enriquecimiento cultural y al fortalecimiento de la economía, la circulación, la educación, la literatura e incluso la gastronomía y el deporte, le realiza un seguimiento a la jurisprudencia que condicionaba a los extranjeros, desde la Ley 16 de 1865, hasta la Ley 103 de 1927. Sin embargo, antes de referirnos a las leyes acotadas, posteriores a la expedición de la Constitución de 1886, vale mencionar lo planteado por García Estrada en otro texto. Esto es, que la política inmigratoria "adoptada desde los albores de la República”, si bien intentó seducir a obreros, artesanos, empresarios y mano de obra calificada, mediante el ofrecimiento de facilidades para el viaje y de tierras para su asentamiento en Colombia, fracasó "desde sus comienzos" (García, 2010: 128), pues los barcos no llegaron cargados de inmigrantes.

Y es importante tal mención, puesto que la Constitución de 1886, si bien "era rígidamente centralista" (Bushnell, 2007: 209), no produjo "cambios significativos en el tema de la inmigración, entre otras razones porque los gobernantes estaban más conscientes de que al país no vendría una inmigración masiva, sino que continuaría tratándose de individuos y familias sueltos" (García, 2006: 52). Por tanto, las Leyes 65 de 1887, 146 de 1888, 117 de 1892 y 71 de 1917, permitieron el acceso de extranjeros siempre y cuando no perturbaran la nación católica colombiana. ${ }^{3}$

\footnotetext{
En este punto es importante recordar, como lo realiza Frédéric Martínez, que en la Ley 117 de 1892 se indicó: "Una junta gubernamental, compuesta por el ministro de Fomento y cuatro especialistas de la agricultura en zona ecuatorial está encargada de firmar los contratos de concesión con las empresas de inmigración. El presupuesto de la junta será de 150.000 pesos anuales" (Martínez, 1997: 31). A su vez, es relevante apuntar que en la Segunda Conferencia Panamericana que se reunió en la capital de México el 22 de octubre de 1901, se le "reconoció a los extranjeros los mismos derechos civiles de que
} 
Con la promulgación de la Ley 78 de 1919, se implantó la regulación de la entrada de extranjeros al país de manera más decidida. Al decir de García Estrada, "[d]icha ley alertaba a las autoridades de los puertos y fronteras para que evitaran la entrada al país de individuos extranjeros que no presentaran pasaportes auténticos y que por tanto pudieran constituir peligro para el orden y la seguridad de la República” (García, 2006: 56).

Pero no se detuvieron allí las medidas restrictivas, con la emisión de la Ley 48 de 1920 comenzó a exigírseles a los extranjeros un certificado de sanidad que hubiese sido avalado por un médico competente, con el cual se esperaba retener a quienes padecieran de tuberculosis, lepra, tracoma, enajenados mentales, alcohólicos crónicos, epilépticos, idiotas, cretinos, mendigos profesionales, quienes traficaran con prostitutas, anarquistas, comunistas, entre otros (Cfr. García, 2006: 56).

Las mencionadas prohibiciones, al estar vinculadas a las consideraciones médico-psicológicas, pueden relacionarse con las ideas sobre la protección de la nación y el mejoramiento de "la raza" que se estaban propagando en América con el despliegue de las ideas positivistas. No obstante, dado que a la consideración sobre tales ideas se les deben incorporar otros aspectos del proyecto de modernización como el fortalecimiento agrícola y comercial, fue sumamente importante que, mientras con las Leyes 45 y 114 de 1922, se mantuvo, al decir de García Estrada, "un trasfondo racista y discriminatorio con respecto a ciertas procedencias de los potenciales inmigrantes" (García, 2006: 58), ${ }^{4}$ la ratificación de la Convención relativa a los Derechos de los Extranjeros durante la Quinta Conferencia Pana-

gozaran los nacionales y estableció que aquéllos tendrían únicamente las mismas obligaciones o responsabilidades que las que respecto a los nacionales se hallaran establecidas por la Constitución y las leyes respectivas" (García de la Parra, 1926: 107).

4 Las cursivas son mías. Para ilustrar el fomento de la inmigración hacia Colombia, García Estrada refiere la publicación en Hamburgo en 1927, del libro de Rafael Herrán, Kolumbien Ein Handbuch mit Zahlreichen Abbildungen, publicado por la editorial J. J. Augustin. No puede dejar de mencionarse en este contexto que la Ley 114 de 1920, aunque estableció restricciones, tenía el propósito de "propender al desarrollo económico e intelectual del país y al mejoramiento de sus condiciones étnicas, tanto físicas como morales", por lo cual, "el Poder Ejecutivo fomentará la inmigración de individuos y de familias que por sus condiciones personales y raciales no puedan o no deban ser motivo de precauciones respecto del orden social o del fin que acaba de indicarse, y que vengan con el objetivo de laborar la tierra, establecer nuevas industrias o mejorar las existentes, introducir y enseñar las ciencias y las artes y, en general, que sean elementos de civilización y progreso" (Carvajal, 2010: 100). Y es importante esta aclaración, porque dicha ley se convertiría en un precedente importante para el posterior mejoramiento del tratamiento que se le daría a los inmigrantes a Colombia. 
mericana que se reunió en Santiago de Chile en marzo de 1923, permitió un viraje favorable para las inmigraciones hacia territorio colombiano (Cfr. García, 2006: 56).

En la estela de la mencionada Convención, donde se les ratificó a los extranjeros los mismos derechos civiles y las mismas obligaciones y responsabilidades que a los nacionales, ya indicados en la Segunda Conferencia Panamericana de 1901, la promulgación de la Ley 74 de $1926^{5}$ y la Ley 103 de 1927, fomentaron la colonización para la agricultura, mediante la introducción de auxilios económicos y la mesura en la solicitud de documentos, pues, decía en el Informe de la Ley 74 de 1926, in extenso:

La inmigración en Colombia debe atender a tres necesidades bien definidas. La técnica y profesional, que en el profesorado y en las grandes industrias nos traiga el caudal de ciencia y experiencia que han acumulado las naciones más cultas, abandonando nosotros nuestra infantil imaginación de que poseemos material humano suficiente para competir con ellas; la inmigración celular, es a saber: aquella que individualmente se demanda para empleos y oficios determinados, como artesanos, mayordomos, mecánicos, agricultores, en general o especializados, es decir, horticultores, arboricultores, floricultores, sericultores, floresteros, peritos en lechería, en avicultura, en pesquería y piscicultura, alfareros, constructores, etc., que se distribuirán por todo el país a dar vida a nuestras industrias incipientes y enseñanza práctica a nuestros trabajadores; por último, las verdaderas colonias de inmigrantes situadas en aquellas regiones que sean más propicias para desarrollar nuevos centros de población y de riquezas, con las elementales condiciones para ello, como son los caminos de fácil tránsito, los mercados propicios y las garantías de higiene necesarios para no hacer inútiles esfuerzos que nos arruinen y desacrediten (López de Mesa, 1927: 63). ${ }^{6}$

Según las páginas anteriores, puede indicarse que, si bien entre 1865 y 1917 las medidas restrictivas se centraron en que no se alterara el orden nacional colombiano, en 1919 se dieron las primeras

5 En el Anexo I al proyecto de ley y reformatoria de la ley 74 de 1926, sobre fomento de la agricultura y la inmigración, se indica: "El Gobierno organizará en el Ministerio de Industria la Sección de Inmigración y Colonización con el personal y elementos necesarios, bajo la dirección de un Jefe, que tendrá una asignación de $\$ 500$ mensuales y será un individuo especializado en estos asuntos” (López de Mesa, 1927: 78)

6 Debe recordarse que en 1927 se establecieron colonias en la Sierra Nevada de Santa Marta, y en 1928 se creó la Compañía Colombiana de Inmigraciones y Colonización, entre otras, pero fueron actos fallidos de la administración política (Cfr. Rueda, 1989: 366). 
restricciones importantes que condujeron a mayores reglamentaciones para la inmigración hacia 1922. Sin embargo, con el viraje favorable de las leyes de 1923, 1926 y 1927, se facilitó la inmigración, con la condición de que ayudasen en las necesidades de la nación.

En el contexto anterior, esto es, de las necesidades nacionales que favorecerían el fortalecimiento de la nación, las conferencias sobre la cuestión de "la raza" que se impartieron en Bogotá en 1920, pueden resultar explicativas porque estuvieron encaminadas a lo que la Ley 74 de 1926 logró, a saber, hacer explícitas dichas necesidades: la inmigración técnica y profesional, la inmigración celular y el desarrollo de nuevos centros de población y de riquezas. ${ }^{7}$

Las conferencias sobre la raza se impartieron en Bogotá entre el 21 de mayo y el 23 de julio de 1920 en el Teatro Municipal. ${ }^{8}$ Sobre ellas, es importante realizar dos aclaraciones preliminares. En primer lugar, apuntar que fueron convocadas por la Asamblea de Estudiantes de Bogotá, debido al revuelo que estaba generando la tesis desarrollada por Miguel Jiménez López, y que había titulado para el Tercer Congreso Médico Colombiano reunido en Cartagena en enero de 1918, como "Algunos signos de degeneración colectiva en Colombia y en los países similares”. En segundo lugar, especificar lo que habrá de destacarse en esta presentación, esto es, la remisión de la discusión sobre "la raza" hacia la discusión sobre la inmigración, dado que fue este último el factor principal que impulsó las restricciones, ya señaladas más arriba.

La organización de las conferencias sobre "la raza" tuvo como precedente la publicación de "Algunos signos de degeneración colectiva en Colombia y en los países similares”, de Miguel Jiménez

\footnotetext{
No puede olvidarse que esta discusión sobre "la raza" hizo parte de un compendio de debates sobre qué era la nación, entre finales del siglo XIX y las primeras décadas del siglo XX en muchos países del mundo. En Francia, por ejemplo, la conferencia dictada por Ernest Renan en la Sorbona, el 11 de marzo de 1882, intitulada “QQué es una nación?”, consignó de manera clara que la nación no podía establecerse mediante la vinculación de la raza, la lengua, la religión, el territorio o los intereses comunes, sino que debía entenderse como un principio espiritual, un alma. De este modo, Renan avalaba una idea de nación en la que "[u]na gran agregación de hombres, sana de espíritu y cálida de corazón, crea una conciencia moral que se llama una nación" (Renan, 1882: 12). En Colombia, en cambio, al decir de Álvaro Andrés Villegas, "[e]l conocimiento de la raza y del territorio se volvían, de nuevo, indispensables para la formación, conservación y perfeccionamiento de la nación, tal como lo expresaron múltiples intelectuales de elite. Si bien, la reflexión sobre ambas variables fue intensa durante las cuatro primeras décadas del siglo XX, e incluso se mantuvo con menor fuerza en las décadas posteriores, fue en 1920 el año en el cual encontramos su máxima expresión" (Villegas, 2005: 67). (Cfr. Villegas, 2012).

8 Conferencias que fueron recogidas en el libro Los problemas de la raza en Colombia, que vio la luz el 12 de octubre del mismo año, y que en su primera versión fue editado por Luis López de Mesa.
} 
López. En dicho texto, el autor afirmó: "[N]uestro país presenta signos indudables de una degeneración colectiva; degeneración física, intelectual y moral" (Muñoz, 2011: 73).

Para sostener lo anterior, Jiménez López realizó un recorrido por los factores físicos, los caracteres biológicos y algunas patologías, mediante los cuales planteó los argumentos que apuntaban al sostenimiento de su tesis sobre la decadencia histórica, intelectual y moral de los colombianos. Todo lo anterior, afirmaba, para "hacer con las viejas y proceras estirpes de Colombia lo que Saint Simón hizo respecto a los Condé y Voltaire con la casta de los Guisas: seguir su decadencia a través de varias generaciones, para llegar en poco tiempo de los más altos exponentes a los más tristes residuos de una misma sangre" (Muñoz, 2011: 94).

Indicado lo anterior, en la primera conferencia impartida en el Teatro Municipal el 21 de mayo de 1920, Jiménez López continuó con la tesis que había planteado en su conferencia de 1918, pero añadió esta vez algunas estadísticas que reforzaban los mismos argumentos, y planteó qué hacer. A este respecto, Jiménez López enumeró algunos puntos principales hacia los cuales, consideraba, debía "dirigirse el estudio y la acción de los hombres de ciencia", a saber: 1. señalarle a la población, pobre preferentemente, la alimentación cuantitativa y cualitativa que le convendría más; 2 . implantar medidas de higiene pública y privada; 3 . estimular la actividad corporal entre la clase acomodada -de manera especial a las mujeres-, para combatir el sedentarismo; 4. reglamentar los descansos entre la clase jornalera para contrarrestar el agotamiento; 5. revisar el plan educativo en lo correspondiente a la educación en la cultura física para incidir en la formación de una voluntad firme; 6 . motivar el estudio de la composición de los alimentos y las aguas de las regiones donde se notasen perjuicios en la salud; 7. poner la ciencia y la experiencia al servicio de la lucha contra el alcoholismo, el paludismo, la anemia, la tuberculosis, la lepra, entre otras; y finalmente, 8. crear colonias agrícolas donde, con la introducción de nuevas industrias, se les ofreciese oficio y sustento a los agricultores colombianos (Cfr. Muñoz, 2011: 97-98).

Sin embargo, dado que aquellas soluciones fueron consideradas por Jiménez López como paliativos para la situación reinante porque no atacaban la enfermedad en su origen, esto es, el problema biológico de razas agotadas, que es preciso rejuvenecer, indicó: 
Este es, pues, el remedio radical para nuestra decadencia; una buena y copiosa inmigración. ¿Qué esto implica peligro para la unidad política de nuestras nacionalidades? La historia actual de la Argentina, de los Estados Unidos, del Uruguay nos está enseñando lo contrario: los inmigrantes europeos son bien pronto tan americanos como nosotros mismos. Ello es, sí, un sacrificio, una especie de abdicación del derecho secular de nuestra sangre en América; pero es uno de aquellos sacrificios que redimen, que salvan a un continente de las negras perspectivas que entraña una decadencia completa de sus pobladores (Muñoz, 2011: 133).

En esta misma orientación de la argumentación, Luis López de Mesa, en la segunda conferencia se sumó a la relevancia que debía prestársele a la inmigración, al tiempo que sintetizó en la educación los otros numerales planteados por Jiménez López, defendidos por ciertos espíritus, al decir de López de Mesa. Sin embargo, respecto a tales vías, la educación o la inmigración, puntualizó López de Mesa:

Quienes lo esperan todo de la educación y rechazan la inmigración, oigan estas palabras de un ilustre sabio: 'La evolución mental de los pueblos es muy lenta, y la educación, siendo, como es, un poderoso medio de la vida social, no es el factor primero en la evolución de las sociedades humanas; ella no puede sino crear un hábito; no hace sino organizar lo que la herencia ha transmitido en bloque'. Hasta aquí, los conceptos de Carlos Debierre, Profesor de la Universidad de Lila (Muñoz, 2011: 134).

Después de lo cual, afirmó López de Mesa: "[A]taquemos el mál en el origen: renovemos nuestra sangre, y habremos procedido con cordura y con acierto" (Ibid). ${ }^{9}$

En esta perspectiva, puede comprenderse que las nombradas restricciones de la Ley 74 de 1926 señaladas más arriba, bajo la lente de Jiménez López y López de Mesa correspondían a las demarcaciones necesarias para emprender la reorganización biológica de los colom-

\footnotetext{
9 En este punto es relevante mencionar que catorce años después, el mismo Luis López de Mesa, siendo Ministro de Educación de la administración de Alfonso López Pumarejo, fue el director del programa "que abordó la educación como eje central de acción social": la Campaña de Cultura Aldeana. Más aún, indica Jorge Uribe: "La Campaña de Cultura Aldeana, dirigida por aquellos intelectuales de la polémica de la raza en Colombia, fue la síntesis del desplazamiento de la higiene moral hacia la limpieza corporal. Los objetivos de esta campaña se reflejaron y tradujeron en los diferentes manuales, cartillas y literatura didáctica dirigida a la población campesina y rural cobijada por este programa" (Uribe, 2008: 216).
} 
bianos. Por tanto, alterar el desarrollo genético y hereditario de los colombianos, purificaría la sangre, mejoraría "la raza" y, con ello, podría encaminar los procesos modernizadores sin temores, y con la tranquilidad de quien está convencido de que acertará.

Queda comprobado entonces que tales planteamientos sobre el "mejoramiento de la raza" no estuvieron desconectados de las políticas inmigratorias ni del proceso de conformación y consolidación de la nación. Más aún, dado que intelectuales como los mencionados llegaron a tener cargos burocráticos en el gobierno nacional, al promover una actitud de atención e inclusive de sospecha hacia algunos migrantes que estuviesen interesados en ingresar al país, debieron tener alguna injerencia en lo decidido legislativamente, sin negar que el tránsito para la construcción de las leyes contaba con un congreso que deliberaba cada una de las cuestiones. ${ }^{10}$ Del mismo modo, es interesante encontrar en las tres conferencias abordadas alusiones explícitas a teóricos europeos, evidenciándose con ello la actualidad de la intelectualidad colombiana, pues aquellas discusiones sobre "la raza" se encontraban en curso en América y Europa. ${ }^{11}$

Ahora bien, para establecer una relación entre las consideraciones sobre la religión que estipuló la Constitución de la República de Colombia de 1886, y cómo pudieron condicionar a los judíos interesados en residir en Colombia entre finales del siglo XIX y las primeras décadas del siglo XX en Colombia, debe indicarse que la mencionada Constitución, redactada por Miguel Antonio Caro, combinó un Estado confesional con un Estado laico. Es decir, la

10 Parecemos coincidir con Álvaro Andrés Villegas cuando apunta en las reflexiones finales de su tesis de maestría: "La tensa construcción de una comunidad política imaginada en Colombia [...] se puede enmarcar dentro de una modernización tradicional, que pretendía garantizar la entrada de la nación al concierto de las naciones civilizadas a través de la plena explotación de sus riquezas, de la estabilización de sus caracteres raciales y de la apropiación de las formas de producción y propiedad capitalistas. Para esto se requería la profunda transformación de la población y del manejo territorial" (Villegas, 2005: 121).

11 Adicionalmente, sobre la década de los años de 1920 deben realizarse dos aclaraciones. En primer lugar, que en mayo de 1924, el grupo conservador radical "Los Leopardos" conformado por Silvio Villegas, José Camacho Carreño y Eliseo Arango, publicó un manifiesto con el cual se autoclasificaron como un "bloque nacionalista" que se sustentó "únicamente en estas ideas sillares: La Propiedad, la Familia, la Patria; La Autoridad, que crea el orden causa del progreso, y mantiene la disciplina, base del perfeccionamiento, y La Unidad espiritual, que es la Unidad religiosa. Está también la síntesis doctrinaria del partido conservador: sólo en él puede realizarse la aspiración nacionalista" (Villegas, 1937: 230). Algunos detalles sobre "Los Leopardos", desde sus debates y las caricaturas, véanse: Arias, 2007: 128-227; y Flórez, 2009: 251-271. En segundo lugar, las discusiones sobre la raza y el territorio fueron sugeridas por Laureano Gómez en una conferencia dictada en el Teatro Municipal de Bogotá el 5 de junio de 1928, por tratarse, al decir del autor, de "los dos elementos esenciales de la entidad política que forma la república de Colombia” (Gómez, 1970: 24). 
Constitución estipuló en el Artículo 38 la Religión Católica, Apostólica, Romana, como la de la Nación, pero permitió, mediante los Artículos 39 y 40 la tolerancia religiosa, dado que en ellos se indicó el respeto por las opiniones religiosas diferentes, y por el ejercicio de los cultos que no fueran contrarios a la moral cristiana.

Ahora bien, cuando se le presta atención al Artículo 41, en el que se indica que la educación pública habría de estar organizada y dirigida en concordancia con la Religión Católica, y al Artículo 47 , en el que se clarifica que las asociaciones religiosas debían presentarse ante la autoridad civil, para que pudieran "quedar bajo la protección de las leyes", por tratarse de una "autorización expedida por la respectiva superioridad eclesiástica" (Constitución, 1886: 227), se puede inferir, como lo plantea Adelaida Sourdis Nájera, que algunos judíos que residían en Colombia a finales del siglo XIX, emigraron, o debieron asimilarse al catolicismo de manera urgente (Cfr. Sourdis, 2011: 164-165).

Sin embargo, si bien puede decirse que la Constitución de 1886 correspondió, al decir de Hernando Valencia Villa, a una "vuelta al Estado confesional" como "una de las piedras torales de la arquitectura constitucional de Caro" (Valencia, 2010: 170), ${ }^{12}$ al circunscribir cierta tolerancia religiosa, no hubo una interferencia acentuada en los procesos de asociación e incluso institucionalización que lograron algunos judíos durante aquellas décadas. Pero aquello debería ser abordado en otro artículo. ${ }^{13}$

\section{Conclusión}

Como pudo advertirse, en este artículo se presentó una contextualización de las legislaciones que se produjeron sobre los judíos

\footnotetext{
12 No puede dejar de mencionarse en este punto, que en 1887 el Estado colombiano firmó con la Santa Sede un Concordato, por medio del cual, entre otras medidas, el gobierno colombiano permitió que la Iglesia católica tuviese el control de la instrucción pública, "aceptó asignar a la Iglesia a perpetuidad una 'suma anual líquida', que desde luego se fija en cien mil pesos colombianos, y que se aumentará equitativamente cuando mejore la situación del Tesoro' (art. 25)”, le otorgó la libre capacidad de comprar y poseer, y permitió que los párrocos pudiesen "cobrar a los fieles 'los emolumentos y proventos eclesiásticos, canónica y equitativamente establecidos"' (Díaz, 1989: 218). Para mayores detalles del Concordato, Cfr. Haddox, 1965: 143-148. Sobre la relación entre la iglesia colombiana y el partido liberal, Cfr. Acevedo, 1995: 137-159.

13 Sobre esta cuestión pueden mencionarse algunas referencias, utilizadas, entre otras, en la tesis de maestría que presenté en la Universidad Nacional de Colombia. Sede Medellín en 2012. En tal perspectiva, para brindarle al lector una información preliminar de las asociaciones e institucionalizaciones alcanzadas por los judíos durante este periodo de 1880 a 1930, Cfr. Mesa, 1996; Fawcett, 1998; Bibliowicz, 2005; y Puerta, 2004.
} 
que estuvieron interesados en inmigrar a América y Colombia entre finales del siglo XIX y las primeras décadas del siglo XX. Para realizar tal aproximación, se mencionaron algunas de las razones que provocaron la emigración de los judíos de Asia, incluida Europa, hacia América, y se indicaron algunas legislaciones promovidas, particularmente en Estados Unidos y Colombia, con las cuales se establecieron las condiciones para la inmigración de judíos.

A su vez, al haber contextualizado del proceso de modernización, el salto de lo agrícola a lo industrial como un tránsito significativo, pudo inscribirse la discusión sobre la inmigración de acuerdo con las necesidades de la nación. En ello, la cuestión de "la raza" se convirtió en un aspecto central que no podía ser evadido respecto de las inquietudes existentes sobre la inmigración técnica, profesional y celular, y de los desarrollos requeridos en la población y el uso de sus riquezas.

En esta perspectiva, el ingreso de los judíos a Colombia particularmente, al no solicitar sino estipular que se comprometieran con los programas de desarrollo y progreso que se estaban emprendiendo, se convirtió en la condición para la admisión de su ingreso. Por tanto, de haber tenido que emigrar para vivir, servir se convirtió en la posibilidad para inmigrar 【 


\section{Referencias}

Acevedo Carmona, Darío (1995). "3. La cruz contra la hoz y el martillo". En: La mentalidad de las élites sobre la violencia en Colombia (1936-1949). Bogotá: El Áncora Editores, Instituto de Estudios Políticos y Relaciones Internacionales.

Arias Trujillo, Ricardo (2007). "Los debates". En: Los Leopardos. Una historia intelectual de los años 1920. Bogotá: Universidad de los Andes, Facultad de Ciencias Sociales, Departamento de Historia.

Avni, Haim (1992). Judios en América. Cinco siglos de historia. José Andrés Gallego (coord.). Madrid: Mapfre.

Bushnell, David (2007). Colombia. Una nación a pesar de sí misma. Nuestra historia desde los tiempos precolombinos hasta hoy. Bogotá: Planeta.

Carvajal Godoy, Johman (2010). "Sangre blanca bien escogida. Sobre la ilusión de la igualdad racial en Colombia". En: Domínguez Gómez, Eduardo (Dir. acad.). Todos somos historia, tomo 2, Vida del diario acontecer. Medellín: Canal Universitario de Antioquia.

De Lange, Nicholas (1992). El pueblo judío: odisea a través de los siglos. Madrid: El Prado. Biblioteca Personal Germán Saavedra Soler.

Díaz Díaz, Fernando (1989). "Estado, Iglesia y desamortización". En: Tirado Mejía, Álvaro (dir.). Nueva Historia de Colombia. tomo 2. Bogotá: Planeta.

Fawcett, Louise - Posada Carbó, Eduardo (1998). “Árabes y judíos en el desarrollo del Caribe colombiano, 1850-1950". En: Boletín Cultural y Bibliográfico, Biblioteca Luis Ángel Arango, Vol. 35, No. 49.

Florescano, Enrique (2012). La función social de la historia. México D.F.: Breviarios del Fondo de Cultura Económica.

Flórez López, Carlos A. (2009). "Leopardos y derecha en Colombia. 1919. 1936. Anotaciones a partir de la caricatura política”. En: Diana Luz Ceballos Gómez (ed.). Prácticas, territorios y representaciones en Colombia 1849-1960. Medellín: Facultad de Ciencias Humanas y Económicas, Universidad Nacional de Colombia.

García Estrada, Rodrigo de J. (2010). "Aspectos de la presencia extranjera en la cultura colombiana, siglos XIX y XX”. En: Eduardo Domínguez Gómez (Dir. acad.). Todos somos historia, tomo 2, Vida del diario acontecer. Medellín: Canal Universitario de Antioquia.

García Estrada, Rodrigo de J. (2006). Los extranjeros en Colombia. Bogotá: Planeta.

García de la Parra, Pablo (1926). Colombia en las conferencias panamericanas. Bogotá: Minerva. 
Gómez, Laureano (1970). Interrogantes sobre el progreso de Colombia. Conferencias dictadas en el Teatro Municipal de Bogotá. Bogotá: Editorial Revista Colombiana.

Haddox, Benjamín Edward (1965). Sociedad y religión en Colombia. Jorge Zalamea (trad.). Bogotá: Ediciones Tercer mundo y Facultad de sociología. Universidad Nacional de Colombia.

Hernández, José Ángel (2011). "La emigración judía ¿Colombia, país de asilo? Años 20, 30, 40”. En: Adelaida Sourdis Nájera - Alfonso Velasco Rojas (eds.). Los judíos en Colombia. Madrid-Bogotá: Casa Sefarad-Israel.

López de Mesa, Luis (1927). El problema de la carestía de la vida. Informe. Bogotá: Imprenta nacional. Archivo Personal Luis López de Mesa, Universidad de Antioquia.

Martínez, Frédéric (1997). "Apogeo y decadencia del ideal de la inmigración europea en Colombia, siglo XIX”. En: Boletín Cultural y Bibliográfico, Vol. 34, No. 44.

Mesa Bernal, Daniel (1996). De los judíos en la historia de Colombia. Bogotá: Planeta.

Muñoz Rojas, Catalina (2011). Estudio introductorio "Más allá del problema racial: el determinismo geográfico y 'las dolencias sociales'". Los problemas de la raza en Colombia. Colección Memoria viva del bicentenario. Bogotá: Universidad Colegio Mayor de Nuestra Señora del Rosario.

Ospina, Joaquín. (1939). El pueblo judío. Salamina-Caldas: Editorial Juan C. Franco F. Fundación Antioqueña para los Estudios Sociales (FAES) Universidad EAFIT.

Puerta Gaviria, Adriana (2004). Medellín judía. Historia periodística de la comunidad judía de Medellín. Medellín: Unión Israelita de Beneficencia.

Rueda Plata, José Olinto (1989). "Historia de la población de Colombia: 1880-2000”. En: Tirado Mejía, Álvaro (Dir.). Nueva Historia de Colombia, tomo 5. Bogotá: Planeta.

Sourdis Nájera, Adelaida (2011). "Los judíos en el Caribe Colombiano, 1813-1938”. En: Adelaida Sourdis Nájera - Alfonso Velasco Rojas (eds.). Los judíos en Colombia. Madrid-Bogotá: Casa Sefarad-Israel.

Uribe Vergara, Jorge (2008). "Sociología biológica, eugenesia y biotipología en Colombia y Argentina. (1918-1939)”. En: Santiago Castro Gómez - Eduardo Restrepo. Genealogías de la colombianidad: formaciones discursivas y tecnologías de gobierno en los siglos XIX y XX. Bogotá: Pontificia Universidad Javeriana.

Valencia Villa, Hernando (2010). Cartas de batalla. Una crítica del constitucionalismo colombiano. Bogotá: Panamericana. 
Villegas, Silvio (1937). No hay enemigos a la derecha. (Materiales para una teoría nacionalista). Manizales: Casa Editorial Arturo Zapata. Sala Antioquia, Biblioteca Pública Piloto.

Villegas Vélez, Álvaro Andrés (2005). "Cuando el pueblo se vuelve raza, racialismo, elite, territorio y nación. (Colombia, 1904-1940)". Tesis de maestría en Historia. Medellín: Universidad Nacional de Colombia.

Villegas Vélez, Álvaro Andrés (2012). "Heterologías: pasado, territorio y población en Colombia, 1847-1941)". Tesis de doctorado en Historia. Medellín: Universidad Nacional de Colombia.

\section{Cibergrafía}

Bibliowicz, Azriel (2005). "Intermitencia, ambivalencia y discrepancia: historia de la presencia judía en Colombia", Amérique Latine Histoire et Mémoire. Les Cahiers ALHIM, 2001. En: http://alhim.revues.org/index535. html. Ingreso: abril 8 de 2012.

“Constitución Política de la República de Colombia, 1886”. En: http:// americo.usal.es/oir/legislatina/normasyreglamentos/constituciones/colombia1886.pdf. Ingreso: marzo 23 de 2012.

"EE. UU. Oficina de Inmigración, Informe Anual del Alto Comisionado General de Inmigración", 1924, p. 24 y ss., "Ley de inmigración de 1924. 26 de mayo de 1924". En: http://translate.google.com.co/ translate?hl=es\&sl=en\&u=http://staff.imsa.edu/socsci/jvictory/immigration_progressive/anti_immigration1926.htm\&ei=X2B_T8_bloKY8gT-sI iyBw\&sa $=X \&$ oi $=$ translate $\& \mathrm{ct}=$ result $\&$ resnum $=10 \&$ ved $=0 \mathrm{CG} 4 \mathrm{Q} 7 \mathrm{gEwC}$ TgK\& prev $=/$ search\%3Fq\%3DThe\%2BImmigration\%2BAct\%2Bof\%2B 1924\%2B\%252B\%2Bespa\%25C3\%25B1ol\%26start\%3D10\%26hl\%3Des \%26sa\%3DN\%26biw\%3D1366\%26bih\%3D667\%26prmd\%3Dimvns. Ingreso: Visitado el 5 de abril de 2012.

Renan, Ernest (1882). “Qué es una nación?”. En: http://enp4.unam.mx/ amc/libro_munioz_cota/libro/cap4/lec01_renanqueesunanacion.pdf. Ingreso: febrero 25 de 2013.

"U.S. Department of State. Office of the Historian", "The inmigration Act of 1924 (The Johnson-Reed Act)". En: http://history.state.gov/milestones/1921-1936/ImmigrationAct. Ingreso: abril 5 de 2012. 